\title{
Using self-reports of pain and other variables to distinguish between older women with back pain due to vertebral fractures and those with back pain due to degenerative changes
}

\author{
E. M. Clark ${ }^{1} \cdot$ R. Gooberman-Hill ${ }^{1}$ - T. J. Peters ${ }^{1}$
}

Received: 10 August 2015 / Accepted: 3 November 2015 / Published online: 13 November 2015

(C) The Author(s) 2015, corrected publication March 2018

\begin{abstract}
Summary Women with back pain and vertebral fractures describe different pain experiences than women without vertebral fractures, particularly a shorter duration of back pain, crushing pain and pain that improves on lying down. This suggests a questionnaire could be developed to identify older women who may have osteoporotic vertebral fractures.

Introduction Approximately $12 \%$ of postmenopausal women have vertebral fractures (VFs), but less than a third come to clinical attention. Distinguishing back pain likely to relate to $\mathrm{VF}$ from other types of back pain may ensure appropriate diagnostic radiographs, leading to treatment initiation. This study investigated whether characteristics of back pain in women with $\mathrm{VF}$ are different from those in women with no VFs.

Methods A case control study was undertaken with women aged $\geq 60$ years who had undergone thoracic spinal radiograph in the previous 3 months. Cases were defined as those with VFs identified using the algorithm-based qualitative (ABQ) method. Six hundred eighty-three potential participants were approached. Data were collected by self-completed questionnaire including the McGill Pain Questionnaire. Chi-squared tests assessed univariable associations; logistic regression identified independent predictors of VFs. Receiver operating characteristic (ROC) curves were used to evaluate the ability of the combined independent predictors to differentiate between women with and without VFs via area under the curve (AUC) statistics.
\end{abstract}

E. M. Clark

Emma.Clark@bristol.ac.uk

1 Musculoskeletal Research Unit, School of Clinical Sciences, Southmead Hospital, University of Bristol, Learning and Research Building, Bristol BS10 5NB, UK
Results One hundred ninety-seven women participated: 64 cases and 133 controls. Radiographs of controls were more likely to show moderate/severe degenerative change than cases ( 54.1 vs $29.7 \%, P=0.011$ ). Independent predictors of VF were older age, history of previous fracture, shorter duration of back pain, pain described as crushing, pain improving on lying down and pain not spreading down the legs. AUC for combination of these factors was 0.85 (95\% CI 0.79 to 0.92 ). Conclusion We present the first evidence that back pain experienced by women with osteoporotic VF is different to back pain related solely to degenerative change.

Keywords Back pain · Case control study · Osteoporotic vertebral fracture $\cdot$ Self-reported pain descriptors

\section{Introduction}

Osteoporosis is one of the commonest diseases to affect older women. By the year 2025, it has been estimated that more than 30 million men and women aged 65 and older will be affected in the European Union alone [1]. Vertebral fractures (VFs) are one of the most important sequelae of osteoporosis, with an average of $12 \%$ of postmenopausal women having at least one vertebral deformity, the majority of which are osteoporotic VFs [2]. These women have a reduced quality of life [3] and a modest excess mortality [4] and are at a high risk of further vertebral [5] and other osteoporotic fractures [6]. A key finding from research into the realities of life with osteoporosis is that $58 \%$ of people with VFs have long-term pain [7]. Despite this, less than a third of women with VF come to clinical attention [8]. Back pain from all causes, most notably degenerative spinal disease, is also common in this age group with $19 \%$ of older women reporting back pain [9]. It is not always clear when a report of back pain should trigger referral for 
radiographs, and there is uncertainty about which characteristics of back pain may indicate presence of VF.

Improved identification of women whose back pain may be indicative of VF would provide the opportunity for those women to receive interventions to manage pain and reduce future fracture risk earlier than is presently often the case. As early intervention for osteoporosis $[10,11]$ is known to improve outcomes and reduce the risk of further fractures, achieving more accurate and faster diagnosis has the potential to benefit women and healthcare services. Although guidelines [12] already stress the importance of 'red flags' in cases of low back pain to identify presence of fracture or cancer, these guidelines may not assist in the identification of fractures that are related to osteoporosis rather than trauma. A recent systematic review [13] and accompanying editorial [14] have reviewed the evidence used in the guidance and found that only age, glucocorticoid use, trauma and presence of contusions were confirmed as risk factors for fracture. In addition, the increased risk of fracture was too low to suggest that combining these factors is clinically useful, and this did not, in fact, perform substantially better than clinical judgement. This highlights that there is a need to look again at predictors and descriptors for vertebral fracture.

There has, nonetheless, been progress in understanding the characteristics of VF to assist in the development of screening tools. For instance, our recent published work shows that clinical indicators such as presence of back pain in combination with other features such as history of fracture can assist in identification of older women at risk of prevalent osteoporotic vertebral fracture [15]. In addition, although it was already known that women with multiple VFs report more days of back pain than those with only one VF [16], we have now started to show that site of back pain can indicate the likelihood of VF. In a cohort of 504 women, the presence of lateral waist area pain associated with a 4.5 -fold increased risk of the existence of vertebral fracture [17]. Although these indicators have the potential to enhance identification of women with $\mathrm{VF}$, it remains uncertain whether pain characteristics might provide useful indications of pain related to VF rather than other causes. Characteristics of pain are widely used within medicine to identify cause or type of pain and to match investigations or treatments with cause - for example, a patient's report of 'crushing effort-related' chest pain or 'stabbing' chest pain is used to help to discriminate cardiac pain from pain due to pleural problems. This information has been used in identification of cardiac pain within clinical practice and to raise public awareness of how to recognise possible cardiac pain that requires urgent medical care. Identifying characteristics of back pain relating to VF that are different from those relating to other types of back pain has the potential to achieve similar goals.

The aim of this study was to compare characteristics of back pain experienced by those with and without osteoporotic
VFs. The presence of differences would indicate that it may be possible to develop a questionnaire to help discriminate between those likely and those unlikely to have a VF. In turn, this may yield an indication of who should have diagnostic spinal radiographs and those who are unlikely to have VF and should therefore receive other forms of investigation or treatment.

\section{Methods}

\section{Study design}

This is a case control study of older women with and without vertebral fractures. The study was approved by an appropriate NHS Research Ethics Committee, REC Ethics approval reference $12 / \mathrm{SW} / 0354$.

\section{Study population}

Digital radiological archives from a large district general hospital radiology department were used to identify a population of potential participants who had a thoracic radiograph in the previous 3 months. These radiological archives contain the images from all spinal radiographs performed within the community and secondary care settings from the north of Bristol and South Gloucestershire, South West England, UK. Inclusion criteria were $\geq 60$ years old, female and thoracic radiographs performed in the previous 3 months. Exclusion criteria were spinal surgery or metastases identified on the radiographs. All eligible women were invited to take part in this study by post over a 2-year time span. Recruited individuals were those who returned their completed consent form and questionnaire. Cases were defined as those with a VF identified from their thoracic spinal radiographs by a single reviewer (EC) blinded to other data used in the analyses using the algorithm-based qualitative (ABQ) method [18]. Controls were defined as those without a VF on their spinal radiograph.

\section{Pain data}

Six hundred eighty-three potential participants were approached, and all who agreed to take part self-completed a questionnaire assembled from domains and scales from questionnaires previously validated in UK populations, including the McGill Pain Questionnaire (MPQ) [19], visual analogue scale (VAS) pain intensity and the Keele STaRT Back pain score [20]. Pain variables used in this analysis include pain severity, change in pain over time, descriptive words from the MPQ, lists of activities that increase or decrease pain and pain radiation. 


\section{Other data}

Data were also collected via self-report on socioeconomic status (highest achieved educational qualifications and housing tenure), global rating of overall health (by the EuroQol visual analogue scale (EQ-VAS) on a scale of 0 for worst possible health to 100 for best possible health), known risk factors for fracture (including age, previous fractures, use of glucocorticoids, family history of hip fracture, smoking, alcohol intake and poor vision) and measures of frailty (walking distance, balance problems, falls and concomitant illnesses). Data were also collected from the radiographic image and report including the indication for performing the radiograph, where requests originated from (primary or secondary care), and radiographic feature of degenerative spinal disease. Radiographs were graded according to severity of degenerative change: mild was defined as one or two vertebrae with osteophytes and/or one loss of disc height, moderate was defined as two to five vertebrae with osteophytes and/or two to three loss of disc heights, and severe degenerative spinal disease was defined as more than five vertebrae with osteophytes and/or four or more loss of disc heights. No face-to-face interviews or physical examination were carried out as part of this study.

\section{Sample size, power and statistical analysis}

Our a priori sample size calculation was based on pilot data indicating that $40 \%$ of women identified through the digital radiological archives would have a VF. We planned on recruiting 206 participants to give us $80 \%$ power with a two-sided $5 \%$ significance to identify a difference of $0.4 \mathrm{SD}$ in the measures of the MPQ between women with and without VF. All statistical analyses were performed using Stata 11.2. Chi-squared tests were used to assess univariable associations with categorical data. The continuous variables age and global health state EQ-VAS were assessed using the Wilcoxon ranksum test. For variables relating to back pain, logistic regression was used to estimate odds ratios (ORs) with $95 \%$ confidence intervals (CIs) for the presence of VF. Multivariable logistic regression was used to adjust univariable associations between variables related to back pain and presence of VF for self-report of a diagnosis of osteoporosis as a proxy for knowledge about the presence of a VF. To identify independent predictors of VF, variables were chosen to be included in the logistic regression analyses if the univariable associations had a $P$ value $<0.1$. Backward elimination was used by starting with all candidate variables and eliminating one by one based on $P$ value and pseudo $R$ squared until no further improvement was possible. All excluded variables were reintroduced into the final model to check that the decision to eliminate them was correct. Independent predictors of VFs identified using multivariable logistic regression models were used to generate a final risk score. The risk score was calculated by using the constant and the beta-coefficients corresponding to each variable identified by regression. A receiver operating characteristic (ROC) curve was employed to evaluate the ability of the combined independent predictors to discriminate between women with and without VFs, with in particular the area under the curve (AUC) being calculated. Participants with missing data for specific items were excluded from the relevant analyses. Sensitivity analyses were performed by rerunning some analyses adjusting for self-reported diagnosis of osteoporosis as a proxy for knowledge of the presence of a VF.

\section{Results}

A total of 197 participants were recruited: 64 cases with VFs and 133 controls without VFs. Of the cases, 46 (71.9\%) reported having received a diagnosis of osteoporosis compared to $36(27.1 \%)$ of the controls $(P<0.001)$. As shown in Table 1, cases were older, more likely to have risk factors for fracture, particularly more likely to have had a previous non-VF, more likely to have used steroids for more than 3 months and more likely to report poor vision. Cases were also more likely than controls to report shorter walking distance and have one or more falls per year (Table 1). There was no evidence of differences between cases and controls in terms of global health state, socioeconomic status or presence of concomitant illnesses.

Just under $80 \%$ of all spinal radiographs had been requested by primary care and the remainder by secondary care (hospital setting), with no evidence of a difference between cases and controls. Pain was the major reason for requesting spinal radiographs ( $79.7 \%$ of 64 cases and $80.5 \%$ of 133 controls). Cases were less likely to have features of degenerative change on their spinal radiographs (Fig. 1). Overall, $29.7 \%$ of cases had moderate or severe degenerative change compared with $54.1 \%$ of controls $(P=0.011)$. In addition, all cases had one or more VFs on spinal radiographs; no controls had VF.

No difference was identified in severity of the most recent episode of back pain (7.7 on a $0-10$ VAS among cases compared with 7.6 among controls, $P=0.884$ ). Cases were more likely to describe their pain as being present for a few days or weeks prior to the spinal radiograph compared with controls, who were more likely to have reported their pain being present for months to years (Table 2). Similarly, cases were more likely to describe their pain as brief, momentary or transient compared to controls. Cases were less likely to describe other pain experiences than controls - for example, controls were more likely than cases to have experienced 'horrible/excruciating' toothache, to describe back pain associated with radiation of pain down their leg, and more likely to describe neck pain with their back pain. 
Table 1 Descriptive statistics and univariable comparisons between cases and controls

\begin{tabular}{|c|c|c|c|}
\hline & $\begin{array}{l}\text { Cases with VF } \\
n=64 \\
\text { Mean (IQR) }\end{array}$ & $\begin{array}{l}\text { Controls without VF } \\
n=133 \\
\text { Mean (IQR) }\end{array}$ & $P$ value for difference \\
\hline Age (years) & 76.9 (71.2 to 83.5$)$ & $71.7(67.0$ to 78.0$)$ & $<0.001$ \\
\hline Health state by EQ-VAS & $\begin{array}{l}55(35 \text { to } 75) \\
n(\%)\end{array}$ & $\begin{array}{l}64(47 \text { to } 80) \\
n(\%)\end{array}$ & 0.098 \\
\hline \multicolumn{4}{|l|}{ Socioeconomic status } \\
\hline $\begin{array}{l}\text { Housing tenure } \\
\text { Mortgaged/owned } \\
\text { Private or HA rental } \\
\text { Council rental } \\
\text { Sheltered accommodation or } \mathrm{NH}\end{array}$ & $\begin{array}{l}48(80.0) \\
7(11.7) \\
1(1.7) \\
4(6.7)\end{array}$ & $\begin{array}{l}108(85.7) \\
7(5.6) \\
8(6.4) \\
3(2.4)\end{array}$ & 0.112 \\
\hline \multicolumn{4}{|l|}{ Risk factors for fracture } \\
\hline $\begin{array}{l}\text { Previous non-vertebral fracture } \\
\text { Yes } \\
\text { No }\end{array}$ & $\begin{array}{l}46(73.0) \\
17(27.0)\end{array}$ & $\begin{array}{l}56(42.8) \\
75(57.2)\end{array}$ & $<0.001$ \\
\hline $\begin{array}{l}\text { FH hip fracture } \\
\text { Yes } \\
\text { No } \\
\text { Do not know }\end{array}$ & $\begin{array}{l}12(18.8) \\
43(67.2) \\
9(14.1)\end{array}$ & $\begin{array}{l}20(15.0) \\
101(75.9) \\
12(9.0)\end{array}$ & 0.397 \\
\hline $\begin{array}{l}\text { Use of steroids for }>3 \text { months } \\
\text { Yes } \\
\text { No }\end{array}$ & $\begin{array}{l}18(31.0) \\
40(69.0)\end{array}$ & $\begin{array}{l}14(11.9) \\
104(88.1)\end{array}$ & 0.002 \\
\hline $\begin{array}{l}\text { Poor vision } \\
\text { Yes } \\
\text { No }\end{array}$ & $\begin{array}{l}10(15.6) \\
54(84.4)\end{array}$ & $\begin{array}{l}7(5.3) \\
125(94.7)\end{array}$ & 0.016 \\
\hline \multicolumn{4}{|l|}{ Frailty } \\
\hline $\begin{array}{l}\text { Walking distance } \\
\quad<400 \mathrm{yd} \\
\geq 400 \mathrm{yd}\end{array}$ & $\begin{array}{l}33(57.9) \\
24(42.1)\end{array}$ & $\begin{array}{l}42(35.6) \\
76(64.4)\end{array}$ & 0.005 \\
\hline $\begin{array}{l}\text { Falls } \\
\text { One or more per year } \\
\text { Less than one per year }\end{array}$ & $\begin{array}{l}23(36.5) \\
40(63.5)\end{array}$ & $\begin{array}{l}27(21.1) \\
101(78.9)\end{array}$ & 0.023 \\
\hline $\begin{array}{l}\text { Concomitant illnesses } \\
\text { Yes } \\
\text { No }\end{array}$ & $\begin{array}{l}54(85.7) \\
9(14.3)\end{array}$ & $\begin{array}{l}117(88.6) \\
15(11.4)\end{array}$ & 0.561 \\
\hline $\begin{array}{l}\text { Balance problems } \\
\text { Yes } \\
\text { No }\end{array}$ & $\begin{array}{l}27(42.2) \\
37(57.8)\end{array}$ & $\begin{array}{l}34(25.8) \\
97(73.5)\end{array}$ & 0.056 \\
\hline
\end{tabular}

$E Q-V A S$ EuroQol visual analogue scale, $F H$ family history, $H A$ housing association, $I Q R$ inter-quartile range, $V F$ vertebral fracture
Differences were also identified in exacerbating or relieving factors, particularly those associated with the weather and movement (Table 2). Cases were less likely to describe negative effects of weather on their back pain; conversely, they were more likely to report an improvement in their pain with lying down or staying still. There was no evidence of a difference in how bothersome back pain was between cases and controls. Rerunning analyses adjusting for self-report of a diagnosis of osteoporosis as a proxy for knowledge about the presence of VF did not change the size of effect or direction of association for any of these self-reported pain descriptors (data not shown).

Analysis of the MPQ showed no difference in number of words chosen between cases and controls. However, cases were more likely to use the word 'crushing' to describe their pain (Table 3). Given the numbers involved, the evidence for this association was weak and, moreover, it was partially attenuated after adjustment for self-report of receipt of a diagnosis of osteoporosis as a proxy for knowledge about the presence of VF (Table 3). 
Fig. 1 Percentage of 64 cases (light gray bars) and 133 controls (dark gray bars) with features of none, mild, moderate or severe degenerative change on spinal radiographs

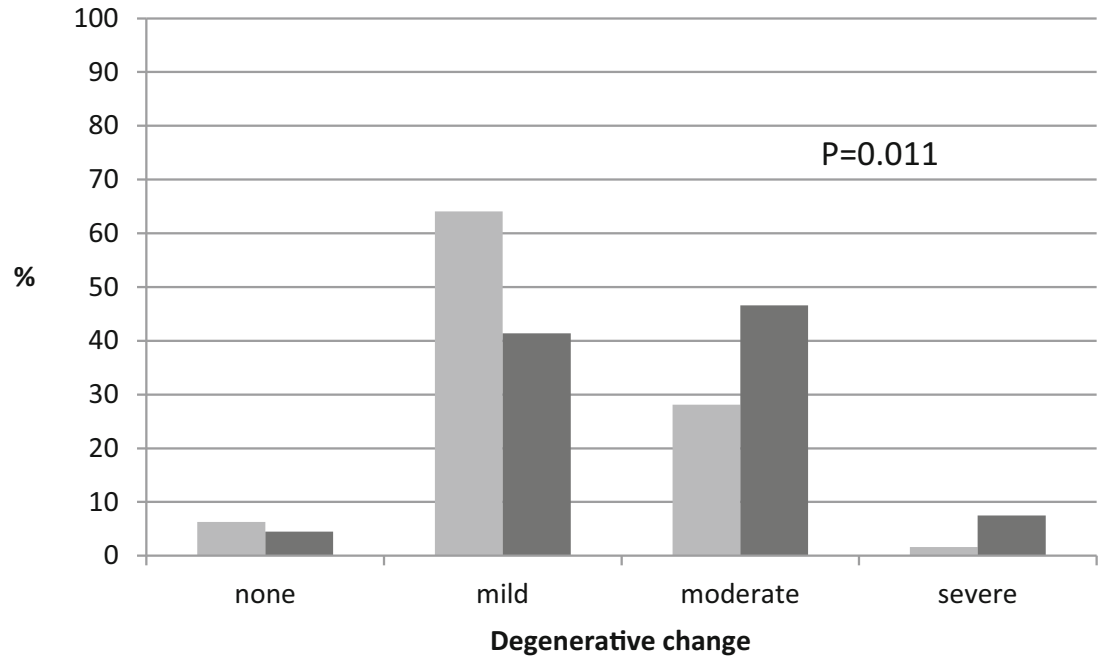

As detailed in Table 4, the independent predictors of VF identified by multivariable logistic regression were age, history of previous fracture, short duration of back pain (days or weeks), pain described as crushing, pain improving on lying down and pain not spreading down the legs. A risk score generated from these six variables discriminated between those with and without VF-for instance, as depicted in Fig. 2a, the median of this score for cases was 0.55 (interquartile range (IQR) 0.40 to 0.70 ) and for controls was 0.20 (IQR 0.02 to 0.37 ). From the ROC analysis shown in Fig. 2b, the AUC was 0.85 (95\% CI 0.79 to 0.92 ). A cut-off of 0.39 gave a sensitivity of 0.77 and a specificity of 0.78 ; this suggests that applying this cut-off to a group of older women with back pain such as those in this study would miss $23 \%$ of those with VF while at the same time reducing the number of radiographs performed by $60 \%$.

\section{Discussion}

We present results from the first study of self-reported pain descriptors in older women with back pain and identify novel predictors for the presence of VF. Combining these risk factors into a simple questionnaire could provide good accuracy for the presence of VF, as defined by the AUC. These results provide the first high-quality evidence that back pain experienced by people with VFs is different to back pain experienced by people with degenerative change. Our novel results require validation and checking within different populations of older people but suggest that a suitable questionnaire could be developed and should be an accurate way of identifying which older women with back pain should have spinal radiographs. Because the presence of an osteoporotic VF is one of the strongest risk factors for future fracture [5, 6], better identification of older women with undiagnosed VFs could allow prescription of currently available medications that reduce future fractures such as hip fracture by $30-50 \%[10,11]$, and this could be cost-effective from a societal perspective.

We identified that people with other pain experiences, particularly neck pain, leg radiation and other horrible or excruciating pain were more likely to be controls - that is were more likely to have degenerative spinal disease — and this is similar to results identified in other studies. For example, clear associations between back pain and leg or neck pain have been reported in community-based populations, with presence of pain in other sites being a strong predictor of subsequent back pain and the need for spinal surgery for degenerative spinal disease [21, 22]. However, as far as we are aware, our finding of a negative association between presence of VF and leg radiation is novel but requires repeating. We have previously carried out a cross-sectional study of 504 women, of whom 37 had VFs and did not identify any association with leg radiation [17], but this may be a reflection of the small number of women with VFs in that study compared with the present study.

We also found that people with back pain without VFs reported negative effects of the weather on their pain. This is similar to previous literature highlighting the high frequency with which this belief is reported, particularly in those with back pain [23] and chronic musculoskeletal pain [24, 25], perhaps reflecting that people with chronic pain feel powerless and view uncontrollable external factors as explanations for their symptoms [26]. However, we did not identify an association between presence of VF and change in pain due to the weather, though again this requires further research to validate this observation. As far as we are aware, we have identified novel associations including a shorter duration of pain in people with VFs and improvement of the pain with no movement, in particular lying down. Development of an osteoporotic VF is likely to be a sudden, new event that may trigger attendance at primary care and a subsequent radiograph. This differs from the trajectories of patients who develop degenerative changes 
Table 2 Self-reported change in pain over time, other pain experiences and exacerbating/relieving factors for back pain in cases with VF and controls, obtained by univariable logistic regression

$\begin{array}{lll}\text { Cases } & \text { Controls } & \text { OR for presence of VF } \\ n(\%) & n(\%) & \text { OR }(95 \% \mathrm{CI}), P \text { value }\end{array}$

Change in pain over time

Duration of pain

Few days to weeks

$28(46.7)$

Months to years

Pattern of pain over time: rhythmic, periodic, intermittent Yes

$32(53.3)$

$24(40.7)$

$35(59.3)$

No

8 (13.6)

Yes

$51(86.4)$

$24(47.1)$

$27(52.9)$

$20(35.1)$

$37(64.9)$

No

Also experienced horrible/excruciating headache Yes

$23(41.1)$

No

$33(58.9)$

With back pain, pain also radiates down their legs Yes

$12(22.2)$

$42(77.8)$

Also have neck pain with back pain Yes

$31(55.4)$

$25(44.6)$

13 (29.6)

$31(70.4)$

19 (38.8)

$30(61.2)$

No

12 (27.9)

$31(72.1)$

Yes

$39(83.0)$

8 (17.0)

5 (11.9)

$37(88.1)$

Exacerbating or relieving factors: movement

Lying down decreases back pain Yes

No

Staying still increases back pain Yes

No

Exacerbating or relieving factors: other

Alcohol decreases back pain

Yes

No

$6(15.4)$

$5(6.2)$

$33(84.6)$
$44(50.0)$

$44(50.0)$

$54(55.1)$

44 (44.9)

38 (42.7)

$51(57.3)$

2.68 (1.40 to 5.16$), P=0.003$

0.67 ( 0.36 to 1.27$), P=0.220$

3.01 (0.99 to 9.11$), P=0.052$

0.42 (0.21 to 0.82$), P=0.011$

0.40 (0.21 to 0.77$), P=0.006$

0.56 ( 0.29 to 1.07$), P=0.077$

0.31 ( 0.15 to 0.66$), P=0.002$

0.35 (0.18 to 0.70$), P=0.003$

0.42 (0.19 to 0.91$), P=0.027$

0.52 ( 0.26 to 1.04$), P=0.064$

0.52 (0.24 to 1.14$), P=0.103$

$58(60.4)$

38 (39.6)

$32(37.2)$

$54(62.8)$

$2.76(0.79$ to 9.70$), P=0.112$

$O R$ odds ratio, $V F$ vertebral fracture 
Table 3 The relationships of self-reported descriptors of back pain from the MPQ in cases with VF compared with controls

\begin{tabular}{|c|c|c|c|c|}
\hline & $\begin{array}{l}\text { Cases } \\
n(\%)\end{array}$ & $\begin{array}{l}\text { Controls } \\
n(\%)\end{array}$ & $\begin{array}{l}\text { OR for presence of } \mathrm{VF}^{\mathrm{a}} \\
\text { OR }(95 \% \mathrm{CI}), P \text { value }\end{array}$ & $\begin{array}{l}\text { OR adjusted for knowledge of osteoporosis } \\
\text { OR }(95 \% \mathrm{CI}), P \text { value }\end{array}$ \\
\hline \multicolumn{5}{|c|}{ Sensory words } \\
\hline Sharp & & & $0.56(0.26$ to 1.23$), P=0.147$ & $0.49(0.21$ to 1.13$), P=0.093$ \\
\hline Yes & $10(15.6)$ & $33(24.8)$ & & \\
\hline No & $54(84.4)$ & $100(75.2)$ & & \\
\hline Crushing & & & 3.02 (1.01 to 9.12$), P=0.050$ & 2.25 (0.69 to 7.34$), P=0.178$ \\
\hline Yes & $8(12.5)$ & $6(4.5)$ & & \\
\hline No & $56(87.5)$ & $127(95.5)$ & & \\
\hline Taut & & & $0.24(0.05$ to 1.06$), P=0.059$ & $0.33(0.07$ to 1.57$), P=0.165$ \\
\hline Yes & $2(3.1)$ & $16(12.0)$ & & \\
\hline No & $62(96.9)$ & $117(88.0)$ & & \\
\hline \multicolumn{5}{|c|}{ Affective words } \\
\hline Tiring & & & 1.73 (0.94 to 3.20$), P=0.078$ & $1.90(0.97$ to 3.74$), P=0.061$ \\
\hline Yes & $29(45.3)$ & $43(32.3)$ & & \\
\hline No & $35(54.7)$ & $90(67.7)$ & & \\
\hline \multicolumn{5}{|c|}{ Evaluative words } \\
\hline Intense & & & 0.49 ( 0.21 to 1.14$), P=0.098$ & $0.46(0.19$ to 1.13$), P=0.092$ \\
\hline Yes & $8(12.5)$ & $30(22.6)$ & & \\
\hline No & $56(87.5)$ & $103(77.4)$ & & \\
\hline \multicolumn{5}{|c|}{ Miscellaneous words } \\
\hline Agonising & & & $0.43(0.15$ to 1.19$), P=0.103$ & $0.35(0.12$ to 1.07$), P=0.066$ \\
\hline Yes & $5(7.8)$ & $22(16.5)$ & & \\
\hline No & $59(92.2)$ & $111(83.5)$ & & \\
\hline
\end{tabular}

$M P Q$ McGill Pain Questionnaire, $O R$ odds ratio, $V F$ vertebral fracture

${ }^{a}$ Obtained from univariable logistic regression models

${ }^{\mathrm{b}}$ Obtained from logistic regression models adjusting for self-report of a diagnosis of osteoporosis as a proxy for knowledge about the presence of a VF

of the spine over many months or years and for whom attendance at primary care may follow a different pattern. However, we know little about the attendance patterns of older women with VF, and more research is needed in this area. Relief of pain from shifting of fractured trabeculae or vertebral cortex from lying down is understandable. It is not clear why women without VF do not receive similar relief from lying down, but muscular spasm [27] or nerve compression [28] are known to be common causes of pain in degenerative spinal disease, and these are unlikely to be improved by lying down.
Our results have important implications for both the clinical and research agendas. We have shown for the first time that back pain experienced by women with VFs is different to back pain experienced by those with degenerative change only. Our results highlight that the absence of descriptors such as pain duration, radiation, pain described as crushing and pain improving on lying down from the current red flag system is an important omission. By validation of our results, including further testing within different populations and possibly combination with physical examination [15], it should be possible
Table 4 Independent predictors of VF

\begin{tabular}{llll}
\hline Variable & OR for VF & $95 \%$ CI & $P$ value \\
\hline Age (years) & 1.09 & 1.03 to 1.16 & 0.005 \\
Previous fracture as an adult & 2.91 & 1.13 to 7.52 & 0.027 \\
Short duration of back pain (days or weeks only) & 5.98 & 2.31 to 15.50 & $<0.001$ \\
Pain described as crushing & 4.35 & 1.01 to 18.74 & 0.048 \\
Pain improved by lying down & 3.34 & 1.05 to 10.69 & 0.042 \\
Pain spreading down legs & 0.21 & 0.07 to 0.61 & 0.004 \\
\hline
\end{tabular}

Results shown are odds ratios (ORs) for the presence of VF adjusted for all other variables in the table 
(A) Box plot for risk score in cases and controls

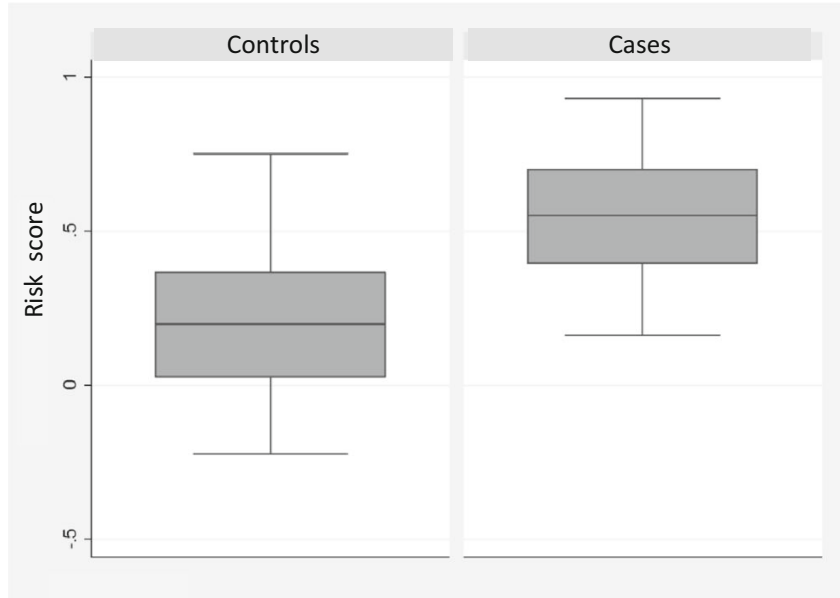

(B) ROC curve

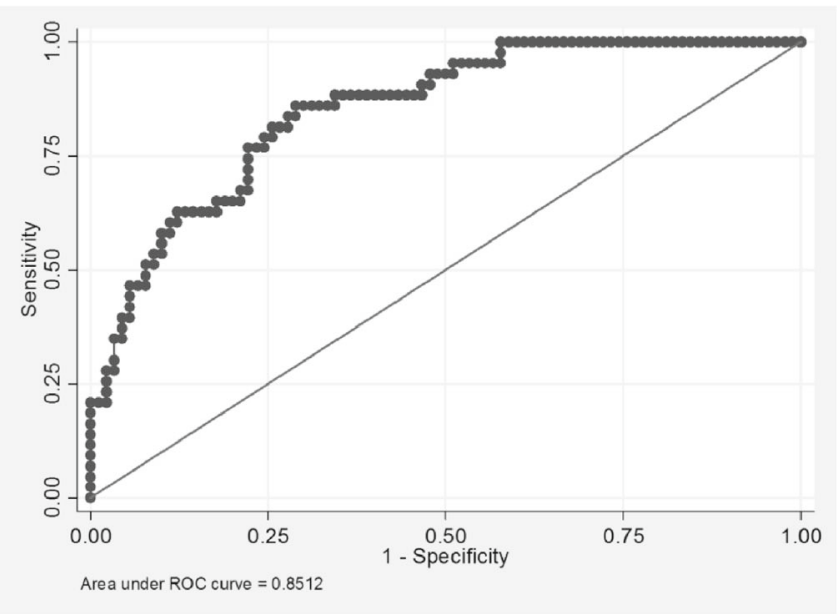

Fig. 2 Analysis of independent risk factors for VF showing a box plot of the distribution of the risk score in cases and controls showing median and IQR with the box and upper/lower values with the whiskers and $\mathbf{b}$ ROC curve for the combination of six variables in Table 4

to develop a questionnaire to identify women with back pain due to osteoporotic VFs, and this may help address the current health care gap where less than a third of women with VF come to clinical attention [8].

There are limitations to this study. Our sample size fell just below that required by our a priori sample size calculation, and as such, we may not have the power to identify some associations. A case control study design always has a risk of bias, and it is possible that the control group is not representative of the population that the cases came from. Another limitation is the potential for cases to know they had a VF. However, we attempted to account for this by adjustment for knowledge of osteoporosis, and this did not substantially change our results. It is possible that by restricting participants to the words within the McGill questionnaire, we will have missed qualities of pain experienced by women with and without VFs, and further qualitative work may be necessary. Finally, consideration of the generalisability of our results is important. As only $30 \%$ of those approached agreed to take part, this may have implications for the generalisability of the results. We did not include men, and this needs to be addressed in future research. In addition, our results may not be generalisable to members of other ethnic groups [29] including non-white women from the UK. Future development of a questionnaire based on these findings should consider these issues to ensure maximum relevance of the questionnaire to the patient population.

In conclusion, we present the first high-quality evidence that back pain experienced by women with osteoporotic VF is different to back pain experienced by women with degenerative change only. This work now needs further development and validation to produce a questionnaire that can be tested with patients to help address the current serious healthcare gap whereby less than a third of women with VF come to clinical attention.

Acknowledgments This work was supported by the Elizabeth Blackwell Institute for Health Research, University of Bristol, and the Wellcome Trust Institutional Strategic Support Fund, Grant code WT ISSF 097822/Z/11/ZR.

\section{Compliance with ethical standards}

Conflicts of interest None.

Open Access This article is distributed under the terms of the Creative Commons Attribution-NonCommercial 4.0 International License (http:// creativecommons.org/licenses/by-nc/4.0/), which permits any noncommercial use, distribution, and reproduction in any medium, provided you give appropriate credit to the original author(s) and the source, provide a link to the Creative Commons license, and indicate if changes were made.

\section{References}

1. Hernlund E, Svedbom A, Ivergard M, Compston J, Cooper C, Stenmark E, McCloskey EV, Jonsson B, Kanis J (2013) Osteoporosis in the European Union: Medical Management, Epidemiology and Economic Burden. A report prepared in collaboration with the International Osteoporosis Foundation (IOF) and the European Federation of Pharmaceutical Industry Associations (EFPIA). Arch Osteoporos 8:136

2. O'Neill TW, Felsenberg D, Varlow J, Cooper C, Kanis JA, Silman AJ (1996) The prevalence of vertebral deformity in European men and women: the European Vertebral Osteoporosis Study. J Bone Miner Res 11(7):1010-1018

3. Dolan P (1997) Modeling valuations for EuroQol health states. Med Care 35(11):1095-1108 
4. Ismail AA, O'Neill TW, Cooper C, Finn JD, Bhalla AK, Cannata JB et al (1998) Mortality associated with vertebral deformity in men and women: results from the European Prospective Osteoporosis Study (EPOS). Osteoporos Int 8(3):291-297

5. Kaptoge S, Armbrecht G, Felsenberg D, Lunt M, O’Neill TW, Silman A et al (2004) When should the doctor order a spine Xray? Identifying vertebral fractures for osteoporosis care: results from the European Prospective Osteoporosis Study (EPOS). J Bone Miner Res 19(12):1982-1993

6. Ismail AA, Cockerill W, Cooper C, Finn JD, Abendroth K, Parisi G et al (2001) Prevalent vertebral deformity predicts incident hip though not distal forearm fracture: results from the European Prospective Osteoporosis Study. Osteoporos Int 12(2):85-90

7. National Osteoporosis Society (2014) Life with osteoporosis: the untold story. Key findings from research into the realities of life with osteoporosis

8. Cooper C, Atkinson EJ, O'Fallen WM, Melton Iii LJ (1992) Incidence of clinically diagnosed vertebral fractures: a populationbased study in Rochester, Minnesota. J Bone Miner Res 7:221-227

9. Hartvigsen J, Frederiksen H, Christensen K (2006) Back and neck pain in seniors - prevalence and impact. Eur Spine J 15(6):802-806

10. Watts NB, Josse RG, Hamdy RC, Hughes RA, Manhart MD, Barton I et al (2003) Risedronate prevents new vertebral fractures in postmenopausal women at high risk. J Clin Endocrinol Metab 88(2):542-549

11. Boonen S, Laan R, Barton I, Watts N (2005) Effect of osteoporosis treatments on risk of non-vertebral fractures: review and metaanalysis of intention-to-treat studies. Osteoporos Int 16(10):12911298

12. NICE (2009) Low back pain: early management of persistent nonspecific low back pain

13. Downie A, Williams CM, Henschke N, Hancock MJ, Ostelo RWJG, de Vet HCW et al (2013) Red flags to screen for malignancy and fracture in patients with low back pain: systematic review. BMJ 347:f7095

14. Underwood M, Buchbinder R. Red flags for back pain (2013) BMJ. 2013;2013(347)

15. Clark EM, Gould VC, Morrison L, Ades AE, Dieppe P, Tobias JH (2012) Randomized controlled trial of a primary care-based screening programme to identify older women with prevalent osteoporotic vertebral fractures. J Bone Miner Res 27(3):664-671

16. Webb R, Brammah T, Lunt M, Urwin M, Allison T, Symmons D (2003) Prevalence and predictors of intense, chronic and disabling neck and back pain in the UK general population. Spine 28(11): 1195-1202
17. Clark EM, Hutchinson AP, McCloskey E, Stone MD, Martin JC, Bhalla AK et al (2010) Lateral back pain identifies prevalent vertebral fractures in post-menopausal women: cross-sectional analysis of a primary care-based cohort. Rheumatology 49:505-512

18. Ferrar L, Jiang G, Schousboe JT, DeBold CR, Eastell R (2008) Algorithm-based qualitative and semiquantitative identification of prevalent vertebral fracture: agreement between different readers, imaging modalities, and diagnostic approaches. J Bone Miner Res 23(3):417

19. Melzack R (1975) The McGill Pain Questionnaire. Major properties and scoring methods. Pain 1975(1):277-299

20. Hill JC, Dunn KE, Lewis M, Mullis R, Main CJ, Foster NE et al (2008) A primary care back pain screening tool: identifying patient subgroups for initial treatment. Arthritis Rheum 59(5):632-641

21. Papageorgiou AC, Croft PR, Thomas E, Ferry S, Jayson MI, Silman AJ (1996) Influence of previous pain experience on the episode incidence of low back pain: results from the South Manchester Back Pain Study. Pain 62(2-3):181-185

22. Vogt MT, Lauerman WC, Chirumbole M, Kuller LH (2002) A community-based study of postmenopausal white women with back and leg pain: health status and limitations in physical activity. J Gerontol 57(8):M544-M550

23. Steffens D, Maher CG, Li Q, Ferreira ML, Pereira LS, Koes BW et al (2014) Effect of weather on back pain: results from a casecross-over study. Arthritis Care Res 66(12):1867-1872

24. Shutty MS, Cundiff G, DeGood DE (1992) Pain complaint and the weather: weather sensitivity and symptom complaints in chronic pain patients. Pain 49:226-228

25. Jamison RN, Anderson KO, Slater MA (1995) Weather changes and pain: perceived influence of local climate on pain complaint in chronic pain patients. Pain 61:309-315

26. Ellegaard H, Pedersen BD (2012) Stress is dominant in patients with depression and chronic low back pain. A qualitative study of psychotherapeutic interventions for patients with non-specific low back pain of 3-12 months duration. BMC Musculoskelet Disord 13:166

27. Steindler A, Luck JV (1938) Differential diagnosis of pain low in the back. JAMA 110:106

28. Beith ID, Kemp A, Kenyon J, Prout M, Chestnut TJ (2011) Identifying neuropathic back and leg pain: a cross-sectional study. Pain 152(7):1511-1516

29. Beaton DE, Bombardier C, Guillemin F, Ferraz MB (2000) Guidelines for the process of cross-cultural adaptation of selfreport measures. Spine 25(24):3186-3191 